\title{
Effectiveness of interventional training program in medical internship program in Gaza Governorates
}

Mohammed Nofal ${ }^{1 *}$, Musa Adam ${ }^{2}$, Yousef Aljeesh ${ }^{3}$

Received: 11 July, 2021, Accepted: 15 Sep, 2021, Published: 10 Oct , 2021

$1 *$ Head of in-service training department, $\mathrm{MOH}$, Gaza, Palestine

2 Administration,Omdurman University, Sudan

3 public health, Islamic University, Gaza, Palestine Email: Mhd2561978@gmail.com

\begin{abstract}
The study's goal was to evaluate the effectiveness of the implementation of a new interventional training program from the trainees' perception. This new interventional training program is formed to strengthening some weakness points found in the assessment old medical internship program. The study consist of three stages (assessment phase occurred already and resulted in some weakness points such as basic medical skills and interpersonal administrative skills. Based on that a new interventional training program is designed and implemented, in the second stage, we designed and implemented the interventional training program accordingly, then evaluation of the new interventional training program was the third stage. Qausi experimental pre-post intervention design was used to compare between old and new intervention. The study population included all medical students (523) who joined and finished the medical internship program in the last three years (2017 - 2019). Data were collected in 10 months through an on line selfadministered questionnaire with a response rate of $81.6 \%$. The study results revealed that more than half of study population in both groups (pre \& post intervention) were male $53.3 \%$ and $54.9 \%$ respectively, and $65.3 \%$ of pre interventional group compared to $81 \%$ of post intervention group were not married. Furthermore, the study's findings revealed a high level of statistical significance following the implementation of the interventional training program, compared to an unsatisfactory level prior to the implementation of the interventional training program. Also, the trainees' perception improved after the interventional program was implemented, with the total mean score of the interventional program being 1.06 out of 2 (53 percent) before the program was implemented compared to 1.66 out of 2 (83 percent) after the program was implemented, with a highly statistically significant difference. According to study findings, interns in a new integrated interventional training program appeared to be very pleased with their new IP.
\end{abstract}

Keywords: Assessment, Effectiveness, Improvement, Medical internship program 


\section{Introduction}

To ensure the desired results of any training program, continuous evaluation must be done on a regular basis, because human health is our most valuable asset. The internship period for physicians must be evaluated and developed over time. This viewpoint is corroborated by the findings of an O'Neill et al, 2016 study, which found that doctors in the new integrated curriculum were more confident in coping with ambiguity, recognising their personal boundaries, and claiming their rights to support when these limits were reached. Another study conducted by Xia et al, 2018, the results confirmed our result concerning of partial reconstruction of old I.P especially in management network system. George et al., 2017, conducted study to assess the improvement of the interns in BLS skills and knowledge after completion of the course in CMC hospital, Ludhiana in India. The results of this study is similar of our study results about integrating the new refreshing courses such as BLS has good, positive effects and improve the interns perceptions about their training Many studies support the idea of reevaluation and produced change to ensure the development and improvement of the internship-training program, that what happened in a study conducted by Ahern et al, 2017. Barriers linked to clinical practices and health care system performance, particularly in high-risk clinical activities, hampered junior doctors' engagement in the complicated contemporary health service environment. Solutions will necessitate re-structuring internship programs to guarantee that intern placements give the requisite safe clinical experience. Another study conducted by A Scicluna et al, 2014 has the same result they evaluate the old Internship Program. A survey undertaken in 2002 of University of New South Wales (UNSW) Medical students stated that their internship instruction was insufficient in various areas. Following that, a few adjustments to the original program were made. However, as part of the main curricular reform process, a distinct PRINT course was designed to be scheduled after the conclusion of final summative evaluations. Despite the fact that PRINT was intended to be the final component of the new outcomes-based curriculum, it was first offered in 2007 as an eight-week course to students enrolled in the old UNSW program.

Another study confirmed that changing in the training methods has good and positive effects 
in changing the perceptions of trainees, so when applying anew change in the training program, the responsible for this change must consider the method of training to grantee the effectiveness of the training by this way. And that what happened when the researcher apply the interventional training program. And this results agree with the results of Mofidi et al., 2015, study Medical education is changing and evolving, according to the statement. To improve student learning, teachers must re-evaluate their medical teaching practices. Another study conducted by Keshk et al, 2018 confirms an improvement in internship nursing trainees' nursing processes following the implementation of a training program, whereas a quasi-experimental research design was carried out on 69 purposive sample of internship trainee nurses in the 2017-2018 internship year, with data collected using two validated reliable tools from Qanowe, 2004. The findings revealed that after the training program was implemented, there was a statistically higher level of knowledge among internship nursing trainees about steps in nursing procedures, compared to an unsatisfactory level before the training program was implemented.

In addition, there is an improvement in internship nursing trainees' nursing processes following the implementation of the training program, with a highly statistically significant difference between the mean of total knowledge scores level before and after the program implementation. There was a strong positive correlation between leadership and management skills, learning and education, communication, security and safety, and different steps of nursing processes among internship trainee nurses, with a highly statistically significant difference at post-implementation of educational program compared to pre-implementation of educational program.

In Palestinian Ministry of Health (MOH). The medical internship in Gaza Strip (G.S) has not been subject to any major evaluation or critical analysis since establishment in 1998, Furthermore, according to the auther knowledge, there is no previous study attempted to evaluate and /or improve the internship program in Gaza strip. Medical internship program had some minor changes in last few years by adding Psychiatry rotation and AnesthesiaIntensive care rotation in addition to computerize the registration system without previous evaluation. 


\section{Methods}

A quasi-experiment comparative study design: (Pre and Post intervention design) was used to evaluate the effectiveness of training program on the medical trainees' doctor in ministry of health. The study was conducted and in agreement with the general directorate of human resource development (GDHRD) at $\mathrm{MOH}$. The research took two years to complete, beginning in June 2018 and ending in July 2020. It is a census survey in which the study populations include all medical trainee doctors who completed their internship program between 2017 and 2019, a total of 523 people. With an 81.6 percent response rate (427\523 participants)

\subsection{Study sample and Sampling}

The sample of this study is census, which consists of 523 interns, almost two third of them participated (353 interns who finished their internship program in Oct 2018) in the evaluation of their internship program (pre intervention group), and the other third (170 interns) who started their newly designed internship program (post intervention group). Census refers to the quantitative study method, in which all the members of the population are units of study.

\subsection{Study instruments}

A structured self-administered questionnaire was designed and developed by the auther after reviewing the related literature. The questionnaire composed of four parts including socio-demographic data, the intern perceptions about the training program for more details are found in our published paper.

\subsection{Study Intervention}

\section{The intervention of this study passed through three stages:}

First stage: Evaluation of existing Situation analysis (pre intervention stage):

More details in recent published paper (citation ) as a results of situational analysis, some weak points were discovered in the internship program. 
The 12-month medical internship program is designed to ensure that graduates of medical schools have gained the required skills to work safely in the medical field. It is divided into two months for each major rotation (Internal Medicine, General Surgery, Pediatrics, Gynecology), one month for primary care, one month for accident and emergency, anesthesia and critical care unit, psychiatry for two weeks for each rotation, and six weeks for elective rotations (four weeks Special medicine and two weeks Special Surgery or vice versa). Rotations are completed in $\mathrm{MOH}$ training hospitals under the supervision of trained trainers. In assessment stage the author evaluate the trainee perceptions about the internship program though a questionnaire adopted by the author, the questionnaire consist of five domains ( role of GDHRD which is responsible for all aspects of medical training program, the design of internship program domain, the content of internship program domain, environment of internship program domain, and the effect domain in the internship program), the result of evaluation were the effects of training program domain was $73 \%$, the design, environment, and the content of training domains as $65 \%, 62 \%$ and $60 \%$ respectively. While the lowest mean score was the role of the general directorate of human resource development (56\%).

The weakness points of medical internship program from the trainees perception can be summarized as following

- There is no clear job description or training plan.

- Inadequate follow-up and supervision - A lack of specific practical training courses such as BLS, ECG and CXR interpretation, Infection Control, Patient Safety, Medical Communication Skills, Medicolegal, Documentation, and Medical Reporting.

- Training is the trainee's duty, and there is no set system to follow.

- -Overcrowding in training centers - Each rotation has no direct supervisor.

- There are no lockers available for trainees (special place for trainees to rest and change clothes). 
Second stage: design and implement the interventional program

Base on the results of the evaluation stage (situational analysis) the weak points and the need for interventional action is explored and discovered, according to that, the interventional training program (ITP) will be designed and implemented.

\section{Contents of ITP}

Our interventional training program (ITP) consist of (10) topics that had the lowest scores in design and content domain regarding the evaluation of old medical internship program from the interns views, and these topics had the approval from the general directorate of human resources development to be applied to the next group of interns. These topics were listed as in the table below:

\section{Table 1: interventional training program contents}

\begin{tabular}{|l|l|l|}
\hline No. & Topic & Training hours/day \\
\hline 1. & Basic life support (BLS) & 6 hours / one full day training \\
\hline 2. & ECG interpretation & 12 hours /two training days \\
\hline 3. & Chest -X- Ray Interpretation & 12 hours /two training days \\
\hline 4. & Infection Control & 6 hours / one full day training \\
\hline 5. & Patient Safety $\quad$ Medical & 12 hours / two training days \\
\hline 6. & $\begin{array}{l}\text { Communication Skills, team } \\
\text { Ethics }\end{array}$ & 6 hours / one full day training \\
\hline 7. & Documentation \& Medical Reports (medico - legal & 6 hours / one full day training \\
\hline 8. & Clinical Audit & 12 hours /two training days \\
\hline 9. & Basics of Research Methodology & 6 hours / one full day training \\
\hline 10. & Basics of Quality Principles & \\
\hline
\end{tabular}

The ITP consist of 84 training hours for each trainee divided by 14 training day over 8 months by one topic every two to three weeks.

Each topic was consist of course description, course outlines, training methods, training logistics, and evaluation tools and carried out by qualified trainers. 
Third stage: evaluation of the effectiveness of the interventional training program

After implementing the interventional training program, the same self-administered questionnaire was distributed to the participants (interventional group) and compare the pre interventional group views to the post interventional group views and evaluate the effectiveness of the interventional training program.

\subsection{Data collection}

The researcher used online questionnaire approach using Google drive as a tool. There were four Steps to create an Online questionnaire, first Create questionnaire form by add / edit questions, then Choose from settings and preview, after that send questionnaire form to the interns Emails, then pause or stop response collection and lastly analyzed responses by download response as a CSV file which can be transferred to Excel sheet.

To get the required response rate, the researcher continuously contacted the interns by phone calls, text messages, and e-mails, reminding them to finish the survey.

\subsection{Validity and Reliability}

Thirty interns were used in a preliminary study. Internal consistency and structure validity were assessed because the correlation coefficients were found to be significant at 0.05 . Furthermore, the validity and reliability of the questionnaire were assessed using Cronbach's Alpha coefficient and the Half Split method; the results confirmed the questionnaire's validity and reliability.

\section{Reliability of the instrument}

The degree of consistency with which an instrument measures the property it is designed to measure Colorado State University is known as its reliability (CSU, 2009). After the pilot stage, and after all of the data had been collected and entered, the reliability test was conducted.

The scale's reliability was (0.943); table 2 gives the reliability test results for all domains. 
Table 2: Reliability estimates for domains and the entire scale

\begin{tabular}{|l|l|l|}
\hline Domains & Cronbach's Alpha & $\begin{array}{l}\text { Split-Half } \\
\text { Coefficient }\end{array}$ \\
\hline Role of Human Resources directorate in training domain & 0.838 & 0.735 \\
\hline Design domain & 0.843 & 0.801 \\
\hline Content domain & 0.869 & 0.749 \\
\hline Environment domain & 0.835 & 0.797 \\
\hline Effect of training program domain & 0.927 & 0.861 \\
\hline Overall & 0.961 & 0.867 \\
\hline
\end{tabular}

\section{Table 3: Validity}

\begin{tabular}{|l|l|l|}
\hline Domains & Correlation & Sig. \\
\hline Role of Human Resources directorate in training domain & 0.783 & 0.001 \\
\hline Design domain & 0.881 & 0.001 \\
\hline Content domain & 0.896 & 0.001 \\
\hline Environment domain & 0.793 & 0.001 \\
\hline Effect of training program domain & 0.836 & 0.001 \\
\hline
\end{tabular}

P-value $\leq 0.05$ was considered statistically significant, with a confidence interval of $95 \%$.

\subsection{Data entry and analysis}

Using SPSS version 23, a data entry model was created, questionnaires and variables were coded, and the database was created. The Excel software was used to enter and code openended queries. In addition, around $5 \%$ of the entered data was subjected to a reentry test. The data was then cleansed by looking for nonsensical numbers and confirming the frequency of all variables.

For each question, general frequencies were used to figure out the responses and detect missing data. Negatively phrased questions were converted when the mean was determined, resulting in data recording and processing. As a result, the total scaling followed a reasonable pattern: higher values suggest more favorable circumstances. In addition, descriptive frequencies, mean, percentage, standard deviation (SD), and frequency tables were used to assess central tendency. To determine the statistical significance of differences, the researcher performed inferential analysis. The impacts of factors were investigated using the T-test. 


\subsection{Considerations of morality}

The Helsinki Committee in Palestine provided an official letter of approval to conduct the study. (Appendix 3)

To perform the study at GDHRD, an official letter from the Ministry of Health was obtained. (Annex 4)

Each participant signed a consent form, which included a statement stating that the individual has the right to participate or decline in the study, as well as assurances that participation is optional and that confidentiality will be respected (Annex 1).

\section{Results}

Table (4) showed the distribution of the study population according to the Governorates, were 77 (17.5\%), 195(45.3\%), 60 (15\%), 55 (12.7\%) and 40 (9.5\%), in north, Gaza, middle Zone, khan yours, and Rafah Governorates respectively. Regarding the age of participants at the time of study the results showed $20.4 \%$ of pre interventional group and $46.5 \%$ of post interventional group were 24 years and less $(x 2=67.379, p=0.000)$ and more than half the study pop in both pre interventional group and post interventional group were male (52(53.3\%)), 78(54.9) respectively $(\mathrm{x} 2=0.097, \mathrm{p}=0.755)$. Regarding marital status, 186 $(65.3 \%)$ of pre interventional group and $115(81 \%)$ of post interventional group were not married and $205(71.9 \%)$ of pre interventional was refugee and $99(39.7 \%)$ was not refugee in post interventional group. Furthermore, $(41.1 \%)$ of post interventional group stated that there is a family member as physician was their bother, while (34.2\%) of pre interventional group stated that brother is physician. Regarding high school weighted average, the study results revealed that $178(62.5 \%)$ of pre interventional and $114(80.3 \%)$ of post intervention group got above $95 \%$ in high school weighted average and $63(22.1 \%)$ of pre interventional, $35(24.6 \%)$ of post international group has accumulation bachelor degree weighted average more than $85 \%$. While most of study pop was graduated from national universities 189 $(66.3 \%)$ of pre interventional and $121(85.2 \%)$ of post interventional group respectively. 


\section{ISRAA UNIVERSITY JOURNAL OF APPLIED SCIENCE}

Table 4: General characteristics of study Population

\begin{tabular}{|c|c|c|c|c|}
\hline \multirow[t]{2}{*}{ General characteristics } & $\begin{array}{l}\text { Pre }- \text { intervention group } \\
(\mathrm{n}=285)\end{array}$ & $\begin{array}{l}\text { Post }- \text { intervention. group } \\
(n=142)\end{array}$ & \multirow[t]{2}{*}{$\chi^{2}$} & \multirow[t]{2}{*}{ P-value } \\
\hline & $\mathrm{n}(\%)$ & $\mathrm{n}(\%)$ & & \\
\hline \multicolumn{5}{|l|}{ Age (years) } \\
\hline 24 Years and less & $58(20.4)$ & $66(46.5)$ & \multirow[b]{3}{*}{67.38} & \multirow[b]{3}{*}{$<0.001$} \\
\hline 25 Years & $88(30.9)$ & $62(43.7)$ & & \\
\hline 26 Years & $74(26.0)$ & $10(7.0)$ & & \\
\hline \multicolumn{5}{|l|}{ Sex } \\
\hline Male & $152(53.3)$ & $78(54.9)$ & 0.10 & 0.75 \\
\hline Female & $133(46.7)$ & $64(45.1)$ & & \\
\hline \multicolumn{5}{|l|}{ Marital Status } \\
\hline Single & $186(65.3)$ & $115(81.0)$ & \multirow[t]{2}{*}{$11.26 \mathrm{a}$} & \multirow[t]{2}{*}{$<0.001$} \\
\hline Married & $99(34.7)$ & $27(19.0)$ & & \\
\hline \multicolumn{5}{|l|}{ Governorates } \\
\hline North & $54(18.9)$ & $23(16.2)$ & \multirow{5}{*}{$2.58 \mathrm{a}$} & \multirow{5}{*}{0.63} \\
\hline Gaza & $132(46.3)$ & $63(44.4)$ & & \\
\hline Middle zone & $35(12.4)$ & $25(17.6)$ & & \\
\hline Khan Younis & $38(13.3)$ & $17(12.0)$ & & \\
\hline Rafah & $26(9.1)$ & $14(9.9)$ & & \\
\hline \multicolumn{5}{|c|}{$\begin{array}{l}\text { Are there another physician at } \\
\text { your home }\end{array}$} \\
\hline Yes & $117(41.1)$ & $60(42.3)$ & \multirow[t]{2}{*}{$0.06 \mathrm{a}$} & \multirow[t]{2}{*}{0.81} \\
\hline No & $168(58.9)$ & $82(57.7)$ & & \\
\hline \multicolumn{5}{|l|}{ If yes there are } \\
\hline Father & $41(35.0)$ & $13(21.3)$ & \multirow{4}{*}{3.63} & \multirow{4}{*}{0.30} \\
\hline Mother & $4(3.4)$ & $3(4.9)$ & & \\
\hline Brother & $40(34.2)$ & $25(41.0)$ & & \\
\hline Sister & $32(27.4)$ & $20(32.8)$ & & \\
\hline \multicolumn{5}{|l|}{ Refuge } \\
\hline No & $80(28.1)$ & $99(69.7)$ & & \\
\hline Yes & $205(71.9)$ & $43(30.3)$ & 67.52 & $<0.001$ \\
\hline \multicolumn{5}{|c|}{$\begin{array}{l}\text { Year of high school } \\
\text { graduation }\end{array}$} \\
\hline Less than 2009 & $47(16.5)$ & $4(2.8)$ & & \\
\hline 2010 & $76(26.7)$ & $2(1.4)$ & & \\
\hline
\end{tabular}


ISRAA UNIVERSITY JOURNAL OF APPLIED SCIENCE

Volume 5 :Issue1, October, 2021

ISSN: 2523-0522

\begin{tabular}{|c|c|c|c|c|}
\hline 2011 & $90(31.6)$ & $1(0.7)$ & \multirow[b]{3}{*}{318.62} & \multirow[b]{3}{*}{$<0.001$} \\
\hline 2012 & $72(25.2)$ & $23(16.2)$ & & \\
\hline 2013 & $0(0.0)$ & $112(78.9)$ & & \\
\hline \multicolumn{5}{|c|}{$\begin{array}{l}\text { High school weighted average } \\
(\%)\end{array}$} \\
\hline Less than $90 \%$ & $57(20.0)$ & $20(14.1)$ & \multirow[t]{3}{*}{16.14} & \multirow[t]{3}{*}{$<0.001$} \\
\hline $91-95 \%$ & $50(17.5)$ & $8(5.6)$ & & \\
\hline More than $95.0 \%$ & $178(62.5)$ & $114(80.3)$ & & \\
\hline \multicolumn{5}{|l|}{ Education } \\
\hline $\mathrm{BS}$ & $281(98.6)$ & $140(98.6)$ & \multirow[t]{2}{*}{0.000} & \multirow[t]{2}{*}{0.99} \\
\hline MS & $4(1.4)$ & $2(1.4)$ & & \\
\hline \multicolumn{5}{|c|}{$\begin{array}{l}\text { Bachelor's degree weighted } \\
\text { average }(\%)\end{array}$} \\
\hline Less than $75 \%$ & $68(23.9)$ & $21(14.8)$ & \multirow{4}{*}{4.74} & \multirow{4}{*}{0.19} \\
\hline From 76 to $80 \%$ & $64(22.5)$ & $35(24.7)$ & & \\
\hline From 80 to $85 \%$ & $90(31.5)$ & $51(35.9)$ & & \\
\hline Above $85.0 \%$ & $63(22.1)$ & $35(24.6)$ & & \\
\hline \multicolumn{5}{|c|}{$\begin{array}{l}\text { Place of medical degree } \\
\text { Graduation }\end{array}$} \\
\hline Palestine & $189(66.3)$ & $121(85.2)$ & \multirow[t]{3}{*}{29.95} & \multirow[t]{3}{*}{$<0.001$} \\
\hline Arab Countries & $83(29.1)$ & $9(6.3)$ & & \\
\hline European Countries & $13(4.6)$ & $12(8.5)$ & & \\
\hline
\end{tabular}

All variables of interventional program were collected to gather for both interventional variables in design and content domain in table (5). The independent t-test showed that average of interventional variables was highly statistically significant difference among pre interventional group and post international group in total mean score (1.06 (53\%) vs 1.66 $(83 \%), \mathrm{t}=14.042, \mathrm{p}=0.000)$. The total mean score of post international group is higher in both design and content domains $(1.26(63 \%)$ vs, $1.73(86.5 \%), \mathrm{t}=7.851, \mathrm{p}<0.000)$ and $(0.85(42.5 \%)$ vs $1.59(79.5 \%), t=13.78$, and $\mathrm{p}<0.000)$ respectively. Consequently, the post interventional training program has positive effect in improving the general internship program 
Table 5: Variables of interventional program in design and content domains.

\begin{tabular}{|c|c|c|c|c|c|c|c|c|c|c|}
\hline & \multirow[b]{2}{*}{ Interventional Items } & \multicolumn{3}{|c|}{ Pre interv group } & \multicolumn{3}{|c|}{ Post interv. group } & \multicolumn{3}{|c|}{ Statistical analysis } \\
\hline & & Mean & SD & $\begin{array}{l}\text { Mean } \\
\%\end{array}$ & Mean & SD & $\begin{array}{l}\text { Mean } \\
\%\end{array}$ & $\begin{array}{l}\text { Mean } \\
\text { diff } \%\end{array}$ & $\mathrm{~T}$ & $\mathrm{p}$ \\
\hline B09 & $\begin{array}{l}\text { The Internship program contain the non- } \\
\text { technical aspects (legal, ethical, health } \\
\text { administrative topics, which is necessary for } \\
\text { the physician's work, etc.) }\end{array}$ & 1.22 & 0.82 & 61.0 & 1.60 & 0.53 & 80.0 & 31.41 & $0, \cdot 4$ & $0.00 \cdot$ \\
\hline \multirow[t]{2}{*}{ B10 } & $\begin{array}{l}\text { The Internship program consists of basic } \\
\text { courses for the trainees such as basic life } \\
\text { support (BLS), primary trauma care (PTC), } \\
\text { interpretation of ECG, interpretation of } \mathrm{C}-\mathrm{x}- \\
\text { Ray...ect }\end{array}$ & 1.31 & 0.86 & 65.5 & 1.85 & 0.46 & 92.5 & 41.14 & 7.007 & 0.000 \\
\hline & Total interventional design variables (D2i) & 1.26 & 0.65 & 63.0 & 1.73 & 0.37 & 86.5 & 36.40 & 7.851 & 0.000 \\
\hline C16 & $\begin{array}{l}\text { The Internship program contains lectures in } \\
\text { basic life support (BLS) or primary trauma } \\
\text { care (PTC) ...ect }\end{array}$ & 1.24 & 0.85 & 62.0 & 1.87 & 0.41 & 93.5 & 51.67 & 8.464 & 0.000 \\
\hline C17 & $\begin{array}{l}\text { The Internship program contains lectures in } \\
\text { basics of ECG interpretation. }\end{array}$ & 0.50 & 0.60 & 25.0 & 1.75 & 0.55 & 87.5 & 250.53 & 20.725 & 0.000 \\
\hline \multirow[t]{2}{*}{ C18 } & $\begin{array}{l}\text { The Internship program contains lectures in } \\
\text { basics of } \mathrm{C}-\mathrm{x}-\text { Ray interpretation. }\end{array}$ & 0.52 & 0.63 & 26.0 & 1.73 & 0.52 & 86.5 & 230.02 & 19.746 & 0.000 \\
\hline & $\begin{array}{l}\text { C19 The Internship program contains lectures } \\
\text { in the medical legal aspects \& professional } \\
\text { ethics }\end{array}$ & 0.71 & 0.81 & 35.5 & 1.64 & 0.68 & 82.0 & 131.51 & 11.796 & 0.000 \\
\hline $\mathrm{C} 20$ & $\begin{array}{l}\text { The Internship program contains lectures in the } \\
\text { interpersonal communication }\end{array}$ & 0.77 & 0.84 & 38.5 & 1.62 & 0.65 & 81.0 & 110.79 & 10.633 & 0.000 \\
\hline $\mathrm{C} 21$ & $\begin{array}{l}\text { The Internship program includes lectures in } \\
\text { team work. }\end{array}$ & 0.89 & 0.86 & 44.5 & 1.48 & 0.75 & 74.0 & 65.29 & 6.905 & 0.000 \\
\hline $\mathrm{C} 22$ & $\begin{array}{l}\text { The Internship program contains lectures in } \\
\text { infection control }\end{array}$ & 1.04 & 0.88 & 52.0 & 1.69 & 0.61 & 84.5 & 62.73 & 7.944 & 0.000 \\
\hline $\mathrm{C} 23$ & The Internship program contains lectures in & 1.01 & 0.86 & 50.5 & 1.47 & 0.73 & 73.5 & 46.16 & 5.542 & 0.000 \\
\hline
\end{tabular}




\section{ISRAA UNIVERSITY JOURNAL OF APPLIED SCIENCE}

\section{Volume 5 :Issue1, October, 2021}

ISSN: 2523-0522

\begin{tabular}{|c|c|c|c|c|c|c|c|c|c|c|}
\hline$\infty$ & patient safety & & & & & & & & & \\
\hline $\mathrm{C} 24$ & $\begin{array}{l}\text { The Internship program includes lectures in the } \\
\text { documentation and medical reporting }\end{array}$ & 0.76 & 0.86 & 38.0 & 1.30 & 0.81 & 65.0 & 71.11 & 6.276 & 0.000 \\
\hline $\mathrm{C} 25$ & $\begin{array}{l}\text { The Internship program includes lectures in } \\
\text { clinical audit and health research }\end{array}$ & 1.09 & 0.88 & 54.5 & 1.51 & 0.72 & 75.5 & 37.66 & 4.843 & 0.000 \\
\hline \multirow[t]{2}{*}{$\mathrm{C} 26$} & $\begin{array}{l}\text { The Internship program contains lectures in } \\
\text { quality of health service }\end{array}$ & 0.78 & 0.81 & 39.0 & 1.42 & 0.70 & 71.0 & 83.45 & 8.113 & 0.000 \\
\hline & Total interventional content variables (C3i) & 0.85 & 0.56 & 42.5 & 1.59 & 0.44 & 79.5 & 87.84 & 13.777 & 0.000 \\
\hline
\end{tabular}

\section{Discussion}

The current study showed the results of interns' perceptions was positively changed, whereas the mean score of pre interventional group before implementation the interventional program was 1.06 out of $2(53 \%)$ to be changed to 1.66 out of $2(83 \%)$ and this difference was highly significant. $\mathrm{P}$ value $<0.000$ and that is compatible with result done by University of California, San Francisco (UCSF), They wanted to provide deliberate preparation for both the professional and personal challenges of internship at the School of Medicine. They presented a multidisciplinary, integrated, closing course called "Coda" as part of a newly constructed medical school curriculum. A new training program has been launched. Students have repeatedly given the course high marks in formal reviews.

Between 2005 and 2010, the overall course quality averaged 4.3 to 4.7 on a 5-point Likert scale (where 1 is "poor" and 5 is "excellent"), making it the UCSF School of Medicine's course with the highest overall rating in 2008, 2009, and 2010.

The trainees' qualitative input has centered on a few common issues. The emphasis on practical, "high-yield" clinical material, the review of critical internship information that they may not have been exposed to, and the variety of topics covered are all appreciated by 
trainees. The course's role modeling is praised, and trainees appreciate the confidence it instills prior to internship, calling it a "wonderful note to leave medical school on." They've also indicated areas for improvement, including a greater focus on primary care and the outpatient setting, as well as more small-group sessions that didn't overlap with other sessions they wanted to attend. Coda course content is like our intervention program (refreshment course), which consisted of management of common clinical tools such as (ECG interpretation, X- Ray reading, Emergency procedures such as chest tube, intubation. CPR...etc.), communication skills in its all aspects, procedural /skill labs e.g. BLS, PTC, ACLS, BSS, Airway management and lastly life skills e.g. team work, health quality, and management of stressors, medical ethics and medico - legal aspects ... etc...

Another study support our study findings, Draper and louw, 2012. In 2002, the University of Cape Town (UCT) developed a "new" problem-based medical curriculum. The purpose of this study was to determine final-year medical students' assessments of internship effeciency and the factors that influence competence. In 2007 ( $\mathrm{n}=27), 2008$ ( $\mathrm{n}=27)$, and 2009 ( $n=30$ ), UCT final-year medical students participated in eight focus groups (six per year). Students' expectations for the internship, their perceptions of competence, their priorities for competence, and the elements that influence competence were all covered in the guide questions. Participants were typically optimistic and confident in their ability to begin an internship, and the transition from high school to internship was described as having both personal and professional aspects. Interpersonal skills, theoretical grounding, and intellectual capacity were regarded as strengths by participants, while a lack of basic science knowledge and some procedural abilities were identified as limitations. Personal initiative, drive, and clinical exposure were all factors that influenced competency. The teaching of interpersonal skills and the development of students as lifelong learners were noted as curriculum strengths. Basic science instruction and evaluation, as well as problembased learning, were highlighted as major flaws (PBL). Overall, the participants were enthusiastic about internship and the "new" curriculum, and they felt confident in their ability to begin internship. Their answers emphasize the importance of self-assurance in the development of competence. These findings illustrate the difficulties surrounding students' judgments of competency as well as their perspectives on the content and methods of learning. Students' perceptions of competence are an important indicator of achievement of 
targeted curriculum outcomes, and they give useful information for curriculum improvement.

Another study conducted by Evans et al, 2004 has the same our results when they applied a new interventional program called pre - registration house officer (PRHO)for newly qualified doctor, PRHOs had a low opinion of their ability in all clinical settings and competencies when they first started the program, but after a few months, most perceptions improved.

Also another study results support our study results, whereas Decates et al, 2019 conclude that before and after the creation of the complete MBCHB medical curriculum, they conducted a survey of successive medical school cohorts. The 2013 cohort appeared to be more positive and less negative, both in terms of their sentiments toward psychiatry as a profession and in terms of their personal feelings about it as a vocation (after curriculum revision). Another study conducted by Xia et al, 2018, the results confirmed our result concerning of partial reconstruction of old I.P especially in management network system. According to the findings, 96.3 percent of instructors thought the new system was beneficial in enhancing teaching quality, 92.6 percent of administrators thought it was effective in implementing management, and over $90 \%$ of participants were satisfied with the system.

Finally, this system aids in the strengthening of intern management and the improvement of intern medical knowledge and expertise.

George et al., 2017, conducted study to assess the improvement of the interns in BLS skills and knowledge after completion of the course in CMC hospital, Ludhiana in India. The results of this study is similar of our study results about integrating the new refreshing courses such as BLS has good, positive effects and improve the interns perceptions about their training. In contrast, they used a pre-test questionnaire to examine interns and postgraduate entrants' knowledge and skills, and a post-test questionnaire to compare the scores after they had completed the BLS course.

Another study confirmed that changing in the training methods has good and positive effects in changing the perceptions of trainees, so when applying anew change in the training program, the responsible for this change must consider the method of training to grantee the 
effectiveness of the training by this way. And that what happened when the researcher apply the interventional training program. And this results agree with the results of Mofidi et al., 2015, Medical education, according to the study, is changing and evolving.

To improve student learning, teachers must re-evaluate their medical teaching practices. There is a scarcity of information about the best Basic Life Support (BLS) training approach. Another study conducted by Keshk et al., 2018, confirms an improvement in internship nursing trainees for nursing processes following the implementation of an educational program, whereas a quasi-experimental research design was carried out on 69 purposive sample of internship student nurses in the 2017-2018 internship year, collected using a validated and reliable tool from Qanowe 2004., The first part contains a sociodemographic data sheet relating to internship students' age, gender, department, and hospitals, and the second part is a student's assessment skills sheet that contains 12 domains divided into four main parts relating to personal and professional qualifications, six parts relating to the nursing process, and two parts relating to personal skills and abilities, for a total of eight parts. The findings revealed that after the educational program was implemented, there was a statistically higher level of knowledge among internship nursing trainees about steps of nursing procedures compared to an unsatisfactory level before the educational program was implemented.

In addition, there is an improvement in internship nursing trainees' understanding of nursing processes after the educational program is implemented, with a highly statistically significant difference between the mean of total knowledge scores before and after the program implementation.

There was a strong positive correlation between leadership and management skills, learning and education, communication, security and safety, other skills, and different steps of the nursing process among internship student nurses, with a highly statistically significant difference at post-implementation of educational program compared to pre-implementation of educational program.

Another study conducted by Sien and Tumb, 2012 from University of Limpopo, south Africa consistence with our study results, Good quality supervisors, effective supervision, adequate chance for practical learning, conductive environment, good support system, 
hospital administration, hospital staff, academic possibilities, personal traits, and reasonable work load were highlighted as effective training in I.P. On the other hand Yang et al, 2018 According to their findings, the current assessment program for IM (internal medicine) internship is strong in terms of being programmatic, real-world educationally, impactful, and learner engaged, but it has room for improvement in terms of its time-based arrangements, relative lack of feedback, provision, and lack of quality control measures.

\section{Conclusion}

Medical internship is very crucial and important period of the future doctor's life. It is the integration of theory and practice, enhancing the trust of the future doctors and increased the safety of practice with patients, for that any formal training needs continuous evaluation and measure the extent to which an intervention achieves its intended purpose. In this study, medical internship program was evaluated from all its aspects, the results revealed some weakness, anew change of design and content domain was added to the program and reevaluated again.

The general results of this study provide significant evidence of positive effect of new change on the all internship program from the intern's views.

A new designed refreshment courses was implemented, results of the evaluation after implementation support the needs to evaluate all domains of the program individually, and the evaluation of the new change assured the improvement of the medical internship program. 


\section{References}

Ahern, S., Reid, K., Temple-Smith, M., \& McColl, G. (2017). The effectiveness of the internship in meeting established learning objectives: A qualitative study. Medical Teacher, 39(9), 936-944. https://doi.org/10.1080/0142159X.2017.1322191

De Cates, N., Cates, P., Singh, S., \& Marwaha, S., (2019) Can curriculum design influence medical students' attitudes to psychiatry? A comparison of two different approaches, Medical Teacher, 41:8, 939-948, DOI:10.1080/0142159X.2019.1602253. https://doi.org/10.1080/0142159X.2019.1602253

Draper, C., \& Louw, G. (2012). Competence for internship: perceptions of final-year medical students. Education for Health (Abingdon, England), 25(1), 16-23.

Evans, D., Wood, D., \& Roberts, C. (2004). The effect of an extended hospital induction on perceived confidence and assessed clinical skills of newly qualified pre-registration house officers. Medical Education, 38(9), 998-1001. https://doi.org/10.1111/j.13652929.2004.01908.x

George, C., Jacob, V., Talwar, N., Liddle, D.,(2017). IOSR Journal of Dental and Medical Sciences (IOSR-JDMS) e-ISSN: 2279-0853, p-ISSN: 2279-0861.Volume 16, Issue 12 Ver. VI (Dec. 2017), PP 08-10 www.iosrjournals.org.

Keshk, L., Qalawa, S., Ibrahim, N., (2018). International Journal of NursingDecember 2018, Vol. 5, No. 2, pp. 32-44. ISSN 2373-7662 (Print) 2373-7670 (Online)

Mofidi, m., Rezai, M., Hafezimoghadam, P., Maghsoudi, M., Mosaddegh, R., Aghdam, H., (2015). Hong Kong Journal of Emergency Medicine • September 2015. DOI: $10.1177 / 102490791502200505$

O’Neill, A., Gillis, A., Charania, S., Fitzpatrick, J., Redmond, A., ... Ridgway, P. (2016). Prepared for Practice? Interns' Experiences of Undergraduate Clinical Skills Training in Ireland. Journal of Medical Education and Curricular Development, 3, JMECD.S39381. https://doi.org/10.4137/jmecd.s39381 
Scicluna, H., Grimm, M., Jones, P., Pilotto, L., \& McNeil, P. (2014). Improving the transition from medical school to internship - evaluation of a preparation for internship course. BMC Medical Education, 14(1), 14-23. https://doi.org/10.1186/1472-6920

Sein, N., \& Tumbo, J. (2012). Determinants of effective medical intern training at a training hospital in North West Province, South Africa. African Journal of Health Professions Education, 4(1), 10-14. https://doi.org/10.7196/ajhpe.100

Swaid, A., Elhilu, A., \& Mahfouz, M. (2017). Medical internship training in Saudi Arabia: interns\&rsquo; views and perceptions. Advances in Medical Education and Practice, Volume 8, 121-128. https://doi.org/10.2147/amep.s123119

Xia, O., Ye, J., Lin, A., Chen, Y., Guo, W., Fong, T., ... Zeng, Z. (2019). The efficacy of the new medical internship management network system. Medicine, 98(7), e14435. https://doi.org/10.1097/MD.0000000000014435

Yang, D., Zhang, K., Hou, X., Feng, S., Li, H., Liao, X., Liu,J., \& Kuang, M., (2018): The PROFILE of assessment program for internal medicine internship of Sun Yat-Sen University, Medical Teacher, To link to this article: https://doi.org/10.1080/0142159X.2018.1510177 